\title{
Imagético e História: o visível e o invisível no cotidiano laboral da perícia criminal $^{1}$
}

\section{Imagery and History: the visible and invisible in the daily work of criminal expertise}

Neusa Rolita Cavedon ${ }^{2}$

\begin{abstract}
Resumo
O objetivo do trabalho consiste em proceder a uma análise das fotografias constantes nos laudos elaborados pelos peritos que integram o Departamento de Criminalística, de modo a desvelar o visível e invisível do cotidiano laboral e urbano desde uma perspectiva histórica, tendo por método a etnografia sustentada pelas técnicas de análise de documentos, entrevistas e observação participante. A fotografia como documento integrante do laudo pericial traz, além do real, "a representação" do perito sobre a dinâmica do crime. Essa ambiguidade faz com que desde 1947 a posição das fotos no laudo venha sendo objeto de discussão pelos profissionais da área.
\end{abstract}

Palavras-chave: Imagético. História. Perícia Criminal. Etnografia.

\begin{abstract}
The aim of this work is to analyze the photographs contained in reports prepared by the experts of the Department of Criminology in order to reveal the invisible and visible on daily urban and labor, from a historical perspective. Ethnography is the method used, and it is supported by the technique of documents analysis, interviews and participant observation. The photography as a document related to the expert report also brings, besides the real aspect, "the representation" of the expert about the crime dynamics. This ambiguity provokes that, since 1947, the position of the photos in the report became subject of debate among the professionals of this field.
\end{abstract}

Key words: Imagery. History. Criminal Expertise. Ethnography.

\footnotetext{
1 Trabalho originalmente apresentado no VII Encontro de Estudos Organizacionais da ANPAC, Curitiba, 20 a 22 de maio de 2012.

${ }^{2}$ Doutora e Mestre em Administração pelo PPGA/EA/UFRGS, Mestre em Antropologia Social pelo PPGAS/UFRGS. Bacharel em Ciências Econômicas pela UFRGS e Bacharel em Administração de Empresas e Pública pela UFRGS. Professora Associada da Escola de Administração da UFRGS e Pesquisadora do CNPq. E-mail: nrcavedon@ea.ufrgs.br.
} 


\section{Introdução}

A linguagem imagética adquire status diferenciado em face do contexto em que se insere. No campo das artes, a fotografia ganha destaque por seu caráter estético; no jornalismo, a fotografia documental tenciona dar credibilidade à narrativa escrita; no âmbito acadêmico, a foto pode tanto servir como ilustração, como granjear a condição de substituta da palavra ou, ainda, como sendo capaz de retratar o cotidiano que fica registrado de maneira visível e também invisível.

O presente artigo tem por objetivo, com base nos pressupostos das Ciências Sociais e da História, compreender e analisar o papel da fotografia no trabalho da perícia criminal para além da perspectiva documental que ela possui, na medida em que o imagético auxilia na reconstituição da dinâmica da violência impetrada de forma a recriar/representar a realidade do crime.

A análise realizada tomou como foco central 40 documentos datados de épocas diferentes. A cena no local de crime, a vítima, o entorno, os pertences da vítima, todos esses registros foram observados nas descrições e fotografias que integram os laudos. Cumpre destacar que esses materiais foram analisados de forma contextualizada, uma vez que o método empreendido na pesquisa foi o etnográfico, portanto, observação participante e entrevistas aliam-se ao conjunto de documentos para efeitos de análise.

Cumpre destacar que a fotografia, independentemente das técnicas empregadas para obtê-las ou dos equipamentos utilizados, pode ser entendida como matéria prima para gerar conhecimento, seja conhecimento técnico ou social. No caso da perícia, a ênfase recai sobre o trabalho técnico necessário para a elaboração dos laudos.

Para que o leitor se aproprie do saber que se quer problematizar, inicialmente serão tecidas considerações teóricas sobre o uso da fotografia nas Ciências Sociais e na História, posteriormente discorrer-se-á sobre o trabalho da perícia, para posteriormente analisar as fotografias constantes nos laudos desde uma ótica histórica e social do cotidiano laboral e citadino. 


\section{0 imagético nas ciências humanas e sociais}

Dentre os teóricos que estudaram a fotografia como reveladora de aspectos do social, Barthes figura como um dos precursores com sua obra seminal " $A$ Câmara Clara”, datada de 1980. Nesse trabalho, o referido autor inicia dizendo da reprodutibilidade a que a fotografia permite, de algo que aconteceu uma vez e que não poderá se repetir em sua materialidade existencial. A foto para Barthes (1984, p. 15-16) "é invisível", trata-se de algo que traz consigo seu referente, ambos ficando presos à "imobilidade amorosa ou fúnebre", em meio à dinâmica do mundo. A fotografia para ele apresenta três práticas: a de operator, a cargo daquele que pratica a ação de fotografar; a de spectator, aquele ou aquela que olha; e, spectrum, que em sua acepção seria o olhado e que permite o retorno do morto. O sujeito, pela fotografia, transforma-se em objeto.

Assim, Barthes (1984) reconhece no ato de fotografar as funções de informar, representar, surpreender, fazer significar, dar vontade. Ele não faz referência ao servir como prova documental, todavia, chama a atenção para a captura dos detalhes que são possíveis de serem obtidos mediante o fotografar, de modo que as fotografias falam e ao assim fazê-lo aterrorizam, perturbam, evidenciam que alguém ou algo esteve em determinado lugar, desse modo, passado e realidade são inerentes à fotografia.

Martins (2009) menciona a dor e o sofrimento registrados através das fotografias, a crueza dos fatos é compartilhada por aquele que olha a imagem e o faz pensar sobre a possibilidade de viver outra realidade, onde o horror da violência não se faça presente. No dizer de Martins (2009, p. 23): “A fotografia é uma das grandes expressões da desumanização do homem contemporâneo, sobretudo porque permitiu a separação cotidiana da pessoa em relação à sua imagem". É essa dicotomização que faz com que o praticante de atos ilícitos tenha a sua foto capturada pelos policiais antes mesmo que corpo físico do infrator.

A fotografia entendida como útil é aquela que emite significados para quem a olha. A foto amplia a capacidade de interpretação de uma dada realidade social. Para além do que está visível na foto, existe o invisível capaz de ser escrutinado: "O invisível se torna visível na própria evidência visual e fotográfica contida nas coisas que restaram, de quem esteve lá e já não está. De certo modo, nos resíduos da humanidade dos que partiram, as fotos nos dizem que sociedade é esta [...]" 
(MARTINS, 2009, p. 27). Assim, pela fotografia se busca compreender o significado do oculto, do ausente, pois "resgatando o ausente da imagem compreendemos 0 sentido do aparente, sua face visível" (KOSSOY, 2002, p. 135).

A concepção de Andrade (2002, p. 26) sobre a fotografia diz da capacidade que ela possui de dialogar com a realidade e com a representação desse real, podendo figurar como registro documental de uma dada realidade e também viabiliza uma "visão ampliada das coisas alheias". Ao efetuar o ato de fotografar o indivíduo insere-se na vida de outrem, no âmago do objeto capturado em imagem. Os hábitos, gostos, preferências serão passíveis de identificação. Além disso, a fotografia permite, através do registro de imagens, a apropriação do objeto fotografado que assim não desaparecerá. O uso da fotografia na modernidade aparece no sentido de suprir uma deficiência humana: a redução na capacidade de observação. A fotografia possibilita a observação do global e do detalhe ao mesmo tempo.

A relação entre a representação de algo através da fotografia e a interpretação passível de ser entabulada vai depender da compreensão do contexto de onde emergem as imagens. O cenário dos atores fotografados vai permitir a compreensão daquilo que não foi verbalizado, revelando "a história visual de uma sociedade" (BITTENCOURT, 2004, p. 199).

A fotografia como "expressão da verdade" é um postulado que tem sido reforçado ao longo do tempo, mas essa credibilidade precisa ser relativizada em razão dos possíveis usos e interesses que podem estar por detrás dessa "verdade" imagética. A fotografia mostra fragmentos de um momento, de uma situação que foi congelada no tempo e, portanto, não pode ser tomada como verdade absoluta, posto que, como todo o documento, a fotografia também expressa ambiguidades, omissões calculadas e significados ocultos (KOSSOY, 2002). A fotografia é uma representação do real, trata-se de um documento criado, gerado. Para Kossoy (2002, p. 27):

Seja em função de um desejo individual de expressão de seu autor, seja de comissionamentos específicos que visam uma determinada aplicação (científica, comercial, educacional, policial, jornalística, etc.) existe sempre uma motivação interior ou exterior, pessoal ou profissional, para a criação de uma fotografia e aí reside a primeira opção do fotógrafo, quando este seleciona o assunto em função de uma determinada finalidade / intencionalidade. Esta motivação influirá decisivamente na concepção e construção da imagem final. 
Apesar dessa dualidade documento/representação, não há como negar que a imagem permite desvendar indícios, evidências sobre uma dada realidade: a fotografia testemunha algo. Há uma realidade exterior, aparente, que é o documento. Todavia, a realidade interior é aquilo que fica oculto. $O$ receptor da fotografia vai interpretá-la de acordo com os seus referenciais; devido a isso, a imagem é passível de várias interpretações. As emoções desencadeadas pelo imagético também podem suscitar diferentes interpretações. Daí a afirmação de Kossoy (2002, p. 48) de que a fotografia fixa e torna imutável a realidade, o que the garante a condição de documento, mas incita a diferentes interpretações e lhe dá a qualificação de "documental porém imaginária". A composição imagem/texto pode revelar aspectos ideológicos de quem elaborou essa construção. A sequência em que estão dispostas as imagens pode alterar a interpretação transformando o documento em uma "fiç̧ão documental" (KOSSOY, 2002, p. 55).

\section{História e fotografia}

Este item está assentado exclusivamente nas considerações de Borges (2008) que evidencia, em seu estudo, a trajetória da fotografia dentro do saber histórico. No dizer da referida autora, do século XIX até início do século XX, os historiadores relegaram a fotografia a um plano inferior para efeitos de pesquisa, sendo que, no limite, eles passaram a desconsiderar as fotografias como documento passível de ser investigado pelos pesquisadores da área.

Essa vertente de pensadores enquadra-se na história qualificada como História Metódica, cuja cientificidade era determinada pela noção de que os documentos são dados naturais, sendo necessária tão somente a verificação sobre a autenticidade dos mesmos e a confiabilidade na fonte de onde emanavam esses materiais, quais sejam, dirigentes políticos, militares e civis, os quais eram considerados como sujeitos da história com capacidade de legitimar as fontes de dados. A fotografia, quando presente nas pesquisas dessa corrente, tinha um caráter ilustrativo, servia como atrativo para a leitura do texto, esse sim considerado como relevante. Ela era tão somente uma ilusão do real, algo que comprometia a busca da verdade obtida através da razão. 
A introdução da noção de perspectiva dentro do universo da fotografia vai gerar uma maior credibilidade ao imagético, posto que os estudiosos começaram a acreditar que, através da perspectiva, haveria uma correspondência correta entre realidade e imagem. Mas há que se destacar que essas imagens eram encomendadas por aqueles que detinham o poder, portanto, atendiam a certas manipulações ou recortes da realidade segundo a ótica dos dirigentes, porém, o fato de ser resultado de uma solicitação desses dominantes era justamente o que dava credenciais para a fotografia ser considerada legítima.

O avanço tecnológico dos aparelhos produzidos para capturar imagens oportunizou uma maior proliferação de "profissionais" amadores afeitos a registrarem o cotidiano das pessoas e das cidades e, com isso, muda o olhar daquilo que é fotografado. $O$ imagético já não fica circunscrito ao universo das elites, mas transita por entre a vida das camadas mais simples, dos costumes daqueles que pertenciam aos estratos mais baixos da hierarquia social. Portanto, para os historiadores metódicos esses fotógrafos amadores não tinham legitimidade em sua produção fotográfica, pois a imagem não advinha de uma encomenda de alguém com credibilidade no meio social. Além disso, os historiadores metódicos consideravam a fotografia como sendo o registro do "aqui e agora", algo que se configurava como um impeditivo para a sua utilização, uma vez que para a história metódica o passado é o que realmente importava.

No final do século XIX começa uma mudança de paradigma na História e essa mudança vai fazer com que a fotografia passe a ser incorporada como fonte de pesquisa. A noção da existência de uma única verdade começa a ser questionada nos diferentes ramos do conhecimento e a História não ficará alijada dessa discussão. Assim, os documentos escritos, validados por serem oriundos de uma fonte considerada fidedigna e que representavam a verdade legitimada pela elite, começam a ser postos em xeque. Os dados que eram percebidos como naturais e não como sendo oriundos de um olhar atrelado ao poder, agora serão apenas representativos de uma das possíveis interpretações. Diferentes atores sociais serão convidados a contribuir com suas visões sobre os acontecimentos. $O$ novo paradigma da História vai congregar dados originários de diferentes camadas sociais e contemplar outras fontes que não só os documentos, dando espaço para a incursão da fotografia no âmbito da ciência histórica e de uma concepção científica que advoga pela compreensão e interpretação dos achados, contextualizando-os. O 
imagético sob essa dimensão vai ser entendido como tendo a capacidade de mexer com os sentimentos do ser humano - amor, ódio, encanto, saudade -, e a fotografia tem a propriedade de comunicar, de simbolizar e de representar, ou seja, não é um documento neutro, ela é uma linguagem que não é falsa nem verdadeira, mas sim permite a produção de versões, de construções que podem variar de acordo com os códigos culturais de onde emerge.

O imagético precisa ser analisado sob a ótica do contexto social, cultural, temporal no qual foi concebido, afinal é um fragmento datado que revela aspectos materiais de uma cultura, mas que dentro dessa realidade possui significados e apresenta omissões em face do recorte realizado, traduz os valores simbólicos de quem o produziu. A fotografia configura-se como realidade e ficção:

as imagens fotográficas devem ser vistas como documentos que informam sobre a cultura material de um determinado período histórico e de uma determinada cultura, e também como uma forma simbólica que atribui significado às representações e ao imaginário social (BORGES, 2008, p. 73).

A fotografia será mais uma das fontes para que o historiador venha a conhecer, compreender e interpretar uma dada cultura, não será a única opção, nem será inferior, nem superior, mas irá se aliar a outros elementos em auxílio ao pesquisador que terá mais dados sobre os quais se debruçar para pensar o cotidiano e as práticas sociais daquele grupo que ele pretende analisar.

Sob essa perspectiva teórica há que se delinear no próximo item o caminho trilhado para a obtenção de dados acerca do trabalho da perícia criminal em meio ao espaço citadino.

\section{Método}

O método utilizado foi o etnográfico, entendido como "a arte e a ciência de descrever um grupo humano, suas instituições, seus comportamentos interpessoais, suas produções materiais e suas crenças" (ANGROSINO, 2009, p. 30). As técnicas utilizadas foram entrevistas, observação participante e, no caso deste artigo, de maneira central, a consulta a documentos do Departamento de Criminalística do Rio Grande do Sul. 
Chizzotti (1995) qualifica como documento toda a informação sistematizada e preservada de forma material e que pode ser acessada de maneira durável, ou seja, ao longo do tempo. Os documentos podem estar estocados em bibliotecas, arquivos, museus, bancos de dados e centros de documentação.

No âmbito da História, Arend (1994) chama a atenção para o movimento que começa mais ou menos na década de 1970 na Europa e nos Estados Unidos da América do Norte mudando o enfoque dos estudos para "novos" temas e "novos" objetos de investigação. Essa mudança vai chegar ao Brasil com dez anos de atraso, na década de 1980. A opção por outros objetos e temas gerou a necessidade de fontes outras de pesquisa para além daquelas que vinham sendo utilizadas. A inclusão de cartas, bilhetes, fotografias, prontuários médicos, diários, processos penais, todo esse material representa um acervo importante para a pesquisa histórica. Todavia, Arend (1994) chama a atenção para o fato de que é preciso, no caso dos processos penais, dominar a forma como o processo é elaborado, quais os caminhos trilhados para a organização do mesmo e também ter ciência das partes constitutivas do referido documento, de modo a ser viável a realização das análises. Atentar para as entrelinhas e para os detalhes é relevante em termos de análise histórica, postula a referida autora.

Esses cuidados foram observados na análise dos laudos dos peritos criminais e transpostos para o artigo de modo a dar conhecimento ao leitor sobre o fazer da perícia, o que vem a ser local de crime e como o laudo é elaborado, quais as partes que o constituem. O material documental utilizado nesse estudo tem sua origem no Departamento de Criminalística do Rio Grande do Sul (DC-RS). O Departamento de Criminalística efetua perícias baseadas em conhecimentos científicos. A administração é de competência da diretora e dois chefes de divisão. A diretora é responsável pela administração geral, o chefe da Divisão de Perícias da Capital é responsável por todos os tipos de perícias realizadas na área metropolitana e o chefe da Divisão de Perícias do Interior tem a competência similar relativa aos Postos de Criminalística do Interior do Estado.

A Divisão de Perícias da Capital é formada pelas seguintes seções: Balística Forense; Química-Legal; Informática; Fotografia; Acústica Forense; Perícias Diversas; Levantamento de Locais; Papiloscopia; Engenharia-Legal; Perícias Ambientais; Documentoscopia Forense; e Apoio Administrativo. 
A Divisão de Perícias do Interior está estruturada em Levantamento de Local de Crime e Administração dos Postos do Interior.

Os laudos do Departamento de Criminalística não se encontram organizados de maneira a facilitar o acesso. Arquivados em caixas do tipo arquivo, encontram-se armazenados em duas salas abarrotadas até o teto com material no próprio departamento. Os laudos mais antigos, das décadas de 1950 a 1970, estão encadernados em livros arquivados no prédio da administração geral do InstitutoGeral de Perícias. Assim, a obtenção dos laudos junto ao DC se deu mediante seleção aleatória realizada por um servidor e os laudos das décadas de 1950 a 1970 foram selecionados pela pesquisadora na administração geral, buscando aqueles cujas fotografias fossem mais significativas de modo a atender o objetivo do presente estudo.

Compõem o conjunto de materiais analisados: 4 laudos datados de 1952; 6 laudos de 1957; 3 laudos de 1965; 1 laudo de 1966; 7 levantamentos fotográficos de 1968; 6 laudos de 1973; 1 laudo de 1976; 1 laudo de 1979; 1 laudo de 1983; 1 laudo de 1992; 2 laudos de 1993; 1 laudo de 1995; 1 laudo de 1996; 1 levantamento fotográfico e 1 levantamento papiloscópico de 2010; 3 laudos de 2011, perfazendo um total de 40 documentos. Os laudos são de diferentes setores, com predominância para os documentos de "Local de morte" que representam 30\% (12 em números absolutos) do total. Há que se registrar que algumas seções, tais como Ambiental, Informática e Acústica Forense inexistiam no passado.

De modo a tornar possível a compreensão do trabalho que é realizado anteriormente à construção do laudo, bem como no que se constitui esse documento, os próximos itens serão destinados a delinear o que vem a ser Criminalística, o trabalho dos peritos e, de modo mais pontual, o trabalho dos peritos em local de morte e a construção do laudo.

\section{0 perito e o local de crime}

Silveyra (2006) menciona que para alguns estudiosos a Criminalística é a ponte entre a polícia e a justiça, ao permitir uma relação de prevenção e investigação de um crime e a solução final mediante o processo penal. 
O lema constante na capa dos primeiros Congressos de Criminalística são reveladores do trabalho que é desempenhado pelos peritos profissionais: "O perito é a sentinela da verdade".

Locard (1939) qualifica de perito aquele profissional que tem por incumbência procurar e interpretar os indícios de um crime e cujas qualidades pessoais competência, inteligência e consciência profissional - terão implicações na administração da prova. A ciência e a técnica são acionadas pelos peritos com vistas à realização da atividade pericial.

A sistematização dos conhecimentos, recursos, procedimentos e a implementação desses saberes no levantamento do local do crime, dos vestígios e das evidências ali presentes, acabam por ser descritas e "ilustradas com fotografias e, se necessários, desenhos e esquemas que facilitem a compreensão do trabalho". A dinâmica do crime pode ser delineada pelo perito a partir dos vestígios e evidências encontrados no local, o que the confere a possibilidade de determinar ou excluir hipóteses, particularidades ou circunstâncias atreladas à ocorrência (MALLMITH, 2003, p. 20).

Rabello (1968) usa a metáfora do livro para tecer considerações sobre o que vem a ser "local de crime". Para o referido autor, "local de crime" é onde o criminoso acaba por deixar gravada a história do delito por ele cometido, na medida em que vários aspectos podem ser depreendidos, tais como: as circunstâncias nas quais o crime veio a ocorrer; se houve ou não luta corporal; se a vítima se defendeu; dentre outras tantas indicações. A dificuldade na leitura deste livro, "local de crime", por quem não detenha conhecimento técnico ou mesmo seja iniciante na atividade, é apontada por Rabello (1968), isto porque o criminoso costuma ser ardiloso na tentativa de ocultar, mascarar ou ainda destruir as provas que venham a incriminálo. Assim, os indícios lá estão para serem decodificados pelo "viandante perspicaz, inteligente e hábil o bastante para decifrá-los" (RABELLO, 1968, p. 51) e cujo cuidado no manuseio da obra deve ser redobrado, posto que qualquer descuido resultará na destruição e/ou na perda para sempre de dados relevantes ao desvendamento do crime.

Para que o profissional possa interpretar os indícios, há que primeiramente proceder a coleta de material, o que é chamado de "levantamento do local". É de competência do perito a realização desse procedimento que deve seguir os preceitos da técnica e cujo primeiro ponto a ser atentado é da preservação do local, 
que significa manter, dentro do possível, por parte da autoridade policial, as condições encontradas por ocasião da chegada ao lugar onde o delito foi cometido.

A extensão do que vem a ser "local de crime" não pode ser determinada de maneira padrão, uma vez que a depender da configuração do caso em questão os vestígios podem ser encontrados em amplos espaços. Isto se deve ao fato de que para a materialização de um ilícito, há uma etapa primeira em que o criminoso produz atos de cunho preparatório para a consecução de seu intento, na sequência ele executa o crime e, mormente, busca ocultar os vestígios que possam vir a identificar a autoria. Portanto, nessas diferentes etapas a materialidade da prova pode se configurar em diversos locais que podem estar mais ou menos relacionados (SILVEYRA, 2006). Sobre as especificidades das ocorrências, Lewgoy (1972, p. 767) já havia advertido que "cada crime, ou infração, tem características próprias, únicas, ao lado de outras adaptáveis a um padrão geral”. Tendo por parâmetro características passíveis de serem enquadradas em certo padrão, Lewgoy (1972) enumera as normas cabíveis no levantamento de local.

Estando no local, o perito precisa registrar a hora em que chegou para atender a ocorrência, a autoridade que solicitou a sua presença, bem como a hora em que saiu do local. Comportamentos a serem observados pelos peritos são elencados pelo referido autor. O sigilo é apontado como sendo inerente à função; anotar tudo e não confiar apenas na memória; a paciência e a atenção aos pormenores são relevantes na coleta adequada dos indícios; o empenho do perito na elucidação do crime requer que ele extrapole os limites de suas possibilidades; obstáculos à consecução do trabalho pericial devem ser registrados no laudo; a imprensa não deve ter acesso prévio a informações de qualquer ordem.

Vários tipos de locais são nominados, e detalhados os procedimentos por Lewgoy (1972). A seguir, as prescrições apresentadas com relação aos "locais de morte".

A primeira providência seria o registro fotográfico do local da ocorrência, isso mesmo antes de adentrar no espaço; se for uma casa, há que ser registrada por meio de fotografias a residência em si e o entorno (vizinhança). O registro escrito deve assinalar se o lugar é de difícil ou de fácil acesso; quais as vias de acesso; condições do solo, ou seja, se há calçamento, cobertura por paralelepípedos, chão batido, pedregoso, argiloso, pantanoso, coberto ou não por vegetação (se existir vegetação, mencionar se alta, rasteira, em floração ou não). Devem ser anotadas as 
condições climáticas (se chovia, fazia calor, se havia vento, frio excessivo); se o local apresenta muito ou pouco trânsito, se é ermo; se a casa onde houve o delito é de alvenaria, madeira, um piso, dois pisos, edifício etc.

Em um segundo momento, ao adentrar no local propriamente dito, o perito deve ser cauteloso para não o alterar. Registros fotográficos precisam ser realizados, bem como um croqui contendo detalhes necessários pode ser elaborado pelo próprio perito, para além dos registros fotográficos.

Lewgoy (1972) ainda elenca as questões a serem respondidas com relação ao estado de conservação e detalhes da estrutura da construção: Qual o número de cômodos da casa? Qual a funcionalidade dos mesmos? Quantas portas e janelas existem no imóvel? Elas estavam fechadas ou abertas? Há sinais de que as janelas ou portas tenham sido forçadas? Como as peças da casa se comunicam entre si? Em qual peça se achava o cadáver? Em que posição o corpo se encontrava? Havia algum odor peculiar no local?

O terceiro passo implica analisar o corpo da vítima: a idade aparente, o sexo, as vestes, a cor do cabelo, os ferimentos visíveis; se há sangue, referir a aparência, se seco ou denotando recenticidade, ou mesmo coagulado. Se o ferimento foi causado por arma de fogo ou arma branca, descrever a aparência, a forma, as dimensões, a localização. Deve-se observar as mãos da vítima para ver se há algum objeto nelas, ferimentos, se nas unhas existem fragmentos de pele, pelos, sangue. Após a cuidadosa atenção dada ao corpo é preciso atentar para o entorno da vítima, posição dos móveis, das portas, janelas, objetos; se há alguma arma no local, estojos percutidos, orifícios de entrada de projetil nas paredes, móveis, teto, objetos utilizados contra a vítima no intento de agredi-la e verificar a existência de frascos, copos, remédios. Além disso, é importante vasculhar banheiros, dispensas, armários de remédio, dependendo da suspeita que o perito venha a ter em função dos indícios presentes no local onde o corpo se encontra.

$\mathrm{Na}$ quarta etapa a ser realizada, Lewgoy retoma a relevância de o perito elaborar um croqui que registre a posição do corpo em relação aos demais pertences da casa, a exemplo de fogão, armários ou outros objetos fixos. As distâncias devem ser fixadas, bem como as distâncias do corpo em relação às janelas, às portas. As dimensões dos móveis também requerem registros. 
É recomendado que o croqui seja elaborado a mão livre pelo próprio perito que está atendendo ao local. Uma ressalva merece destaque porque vai ao encontro daquilo que se quer discutir nesse artigo:

Embora a objetivação fotográfica seja indispensável, pode dar com facilidade uma visão inexata, distorcida, das relações dimensionais e da perspectiva dos objetos. Isto acontece, em particular, quando a peça é de pequenas dimensões e possui algum mobiliário (LEWGOY, 1972, p. 775).

A quinta etapa é aquela referente ao levantamento das impressões papilares, a ser realizada logo após o término dos registros preliminares e fotográficos. Superfícies onde possam ser verificadas impressões papilares latentes devem ser periciadas.

A sexta etapa requer o manuseio do corpo da vítima, a retirada das vestes com a correspondente anotação da ordem em que se deu essa ação. As vestes devem ser manuseadas com cuidado para que não venham a ser danificadas, mantendo-as intactas, tal como foram encontradas no corpo da vítima. Novamente há necessidade dos registros fotográficos dos ferimentos. As fotos serão produzidas em face da presença de sangue no corpo da vítima e após a limpeza cuidadosa, sem a presença de sangue, o que vai tornar mais evidente o tipo de ferimento produzido, a exemplo da perfuração por arma de fogo.

Findo o elenco de etapas a serem cumpridas pelo perito, Lewgoy (1972) tece considerações mais gerais sobre o cuidado ao manusear o corpo da vítima, para que projetis à flor da pele ou outros objetos no corpo da vítima não venham a se perder. A existência de pegadas no local deve ser observada em sua orientação e sequência. A presença de lascas, cacos de vidro, óculos, carteiras, pequenos objetos, tudo pode se configurar como indício importante para a elucidação do crime.

Localize, descreva, fotografe, recolha outros elementos de possível importância. [...] Observe se as vestes da(s) vítima(s) estão dilaceradas, ou se faltam botões. Em caso afirmativo, além da objetivação fotográfica desses danos, dê uma boa descrição por escrito dos mesmos (LEWGOY, 1972, p. 776).

Portanto, a perícia através do trabalho realizado em locais de crime, busca analisar todos os vestígios e assim determinar a materialidade do fato ou mesmo apurar uma falsa comunicação de crime. A análise dos vestígios possibilita a qualificação da infração penal, podendo levar à autoria dos crimes. Todos os 
vestígios que compõem a cena do crime são perpetuados através dos registros descritivos e fotográficos.

Silveyra (2006) considera que o valor do registro fotográfico, em se tratando de perícia, concentra-se em sua objetividade, uma vez que a existência física de alguma coisa captada via imagem fotográfica não é passível de discussão. Para o referido autor, a fotografia permite deixar gravada, em perspectiva, objetos e lugares. A realização de várias fotografias no local de crime de forma parcial é que vai auxiliar na composição do conjunto de elementos que irão servir como prova dos fatos e das circunstâncias, elementos necessários para a investigação. Todavia, Silveyra (2006) aconselha a elaboração de um levantamento topográfico de modo a complementar aquilo que foi capturado pelas fotografias.

Mas, esse trabalho de levantamento de local é apenas uma parte daquilo que o perito deve realizar. $O$ trabalho que irá consumir mais tempo será aquele de análise para a compreensão e reconstituição da dinâmica do crime com base nas evidências e que culmina com a elaboração do laudo (MALLMITH, 2003). O laudo, a partir dos materiais examinados, configura-se como sendo a materialização da perícia por meio da escrita (DA COSTA FILHO; ABDALLA-FILHO, 2010) e é sobre essa peça pericial que o próximo item irá tratar.

\section{0 laudo}

O Departamento de Criminalística emite três tipos de documentos. Quando a equipe de plantão é solicitada para comparecer a um local, pela Polícia Civil, não havendo condições de chegar até o referido local em razão, por exemplo, da obstrução da equipe em adentrar ao espaço, é expedido um ofício de informação. $O$ laudo exige que o perito chegue a alguma conclusão, quando isso não é possível o documento emitido é a informação técnica.

O laudo é composto de quatro partes: preâmbulo, exposição, conclusão, encerramento.

O preâmbulo menciona dados sobre a ocorrência: número do laudo, objeto (por exemplo, exame pericial em local de morte), vítima (nome), local dos exames (rua, número, bairro), solicitação (delegacia da polícia civil que solicitou a perícia), número da ocorrência, órgão para a difusão, horário e data de atendimento da 
ocorrência, e números de controle do Departamento de Criminalística (protocolo e requisição).

A exposição traz dados sobre o local do crime e dados da vítima. Com relação ao local é feita menção se o crime ocorreu em um local ermo de baixa densidade demográfica, se havia casas ao redor; se a ocorrência foi à noite; como eram as condições de iluminação; bem como o clima, temperatura, intempéries (chuva torrencial ou não); se o fato se deu em rua asfaltada ou de chão batido; presença ou não de vegetação, se essa vegetação é constituída de árvores, arbustos ou apenas gramíneas. Sobre a vítima, informa-se a posição do corpo; se os membros superiores e/ou inferiores apresentavam-se fletidos ou estendidos ao longo do corpo; posição da cabeça; onde se encontrava o corpo (se em um cômodo da casa ou em via pública); os ferimentos; a posição das vestes, cor e estado da indumentária, manchas de sangue presentes no vestuário; quantidade de sangue no corpo da vítima; cicatrizes; altura aproximada; cor da pele; cabelos (se longos, curtos, grisalhos); adereços que a vítima portava (anéis, pulseiras, relógio, corrente); se o corpo já estava com rigidez cadavérica, com livores, hipóstase, temperatura do corpo ao toque manual. Os objetos encontrados próximos ao corpo também são relatados, a exemplo de armas, componentes de munição, cadeiras, cordas, lençóis, enfim, tudo que possa ter relação com o crime.

Detalhada a parte correspondente à exposição, são tecidas as considerações técnicas, no dizer do perito $\mathrm{J}$ do Departamento de Criminalística do Rio Grande do Sul:

\begin{abstract}
O laudo que a gente tem mais satisfação é aquele que as considerações técnicas são deste tamanho (faz o gesto de grande). A gente tem muita coisa para falar, esse eu acho que é o laudo que tu consegue tirar conclusões e tu consegue fazer muita consideração a respeito dele. Quando está difícil de escrever a consideração técnica, é porque tem realmente muito pouco elemento pra tu falar. Muitas vezes a gente põe sem consideração técnica porque não tem o que dizer. Eu fiz o levantamento e só aquilo que eu posso dizer. Eu só posso dizer daquilo que eu achei, formular hipótese com base naquilo, a hipótese ia ficar muito ampla, não ia ajudar em nada o trabalho do inquérito, não é? (entrevistado)
\end{abstract}

O encerramento se dá mediante as considerações finais que referem terem sido deixados o local e o material que lá havia a cargo da autoridade policial que lá se encontrava e que o corpo ficou para ser recolhido ao Departamento Médico-Legal para a realização dos exames que irão definir a causa letal. É informado o número 
de folhas que integram o laudo, forma de impressão (anverso), número de fotografias e que as mesmas encontram-se numeradas, quem é o perito relator, o perito revisor e o visto da chefia (a Direção do Departamento).

As fotos anexadas ao laudo são numeradas numa sequência que mostra inicialmente o local, o corpo da vítima, detalhes dos ferimentos e objetos que possam estar ligados ao crime. Essa sequência permite o registro documental e, também, uma "visão ampliada das coisas alheias" (ANDRADE, 2002, p. 26). A partir de maio de 2009, todas as fotos passaram a ser digitalizadas.

Dois aspectos geram discussão, no presente, quanto à elaboração dos laudos: a padronização dos laudos e a inserção das fotografias se ao longo ou no final do texto. Mediante a análise dos anais do Primeiro Congresso Nacional da Polícia Técnica, em 1947, foi possível verificar que essas preocupações já eram objeto de questionamentos e reflexões por parte dos peritos daquela época.

Abreu (1950) traz em suas argumentações a relevância da fotografia para o trabalho do perito. O referido autor dá ênfase para a fotografia em laudos grafotécnicos, ao reconhecer que, seja como ilustração ou reveladora de fraudes, a fotografia se mostra como "indispensável e imprescindível ao técnico" (ABREU, 1950, p. 169).

Para Abreu (ibidem), o perito tem consciência desse valor atribuído às fotos na medida em que elas auxiliam no desvendamento de indícios, bem como servem para comprovar as hipóteses e na construção das conclusões. A questão levantada por esse perito dizia da posição das fotografias no laudo. Ao alocá-las no final, após a parte descritiva, isso implicava que o leitor interrompesse a leitura para buscar a visão das fotos no final da peça pericial, essas idas e vindas do texto para as fotos e das fotos para o texto, no entender de Abreu, não se configuravam como sendo algo prático. Além dessa forma de apresentação, outra possibilidade encontrada era a de mesclar as fotos com o texto, mas essa proposição, no caso dos exames grafotécnicos, era desaconselhada em razão das menções do perito se reportarem inúmeras vezes à mesma fotografia, o que implicaria também em um vai e vem no manuseio do laudo.

A proposição de Abreu, visando sanar essas dificuldades, já vinha sendo posta em prática pelo perito e, segundo a sua visão, permitia a minimização dos inconvenientes apontados. 
A seguir o registro da sugestão nas palavras do autor:

Consta esse método do seguinte: o laudo continua formando duas partes independentes - o texto escrito e a parte ilustrativa anexa, dentro de uma capa comum.

Entretanto, os dorsos de ambas as partes, em vez de serem presos juntamente com o dorso da capa, são presos aos bordos exteriores da capa e com as beiras a serem manuseadas para dentro.

Aberta a capa, teremos do lado esquerdo, o laudo propriamente dito e do lado direito, a série de quadros fotográficos ou demonstrativos.

Abrindo-se para a esquerda a parte descritiva do documento técnico, quando necessário, abre-se para a direita o quadro que se deseja observar, sem necessidade de fechar a parte escrita (ABREU, 1950, p. 170).

Éboli (1950), também em épocas remotas, já esboçou sua preocupação com a sistematização dos relatórios e laudos. Engessar demais a elaboração dos laudos através do enquadramento das partes poderia ter implicações futuras, uma vez que o laudo perderia o caráter de individualização de que necessita e que the confere diferencial, dada a natureza do assunto do qual trata. Mas, por outro lado, deixar ao relator a liberdade de distribuir o conteúdo ao longo da peça, denotaria um cunho extremamente pessoal e suscetível de críticas. Assim, a proposição apresentada era de que em função da área específica da perícia fosse elaborado um roteiro padrão. O laudo seria numerado, informaria da legislação que permite a realização da perícia, a autoridade do órgão da perícia que incumbiu os peritos para realizarem o exame, explicitando a ocorrência. Na sequência, viria o histórico dando conta do dia, horário, local, autoridade que solicitou a perícia. A seguir, o exame do local, onde seria elaborada uma descrição detalhada das condições encontradas. Após, as violências observadas no local seriam registradas em tópico específico e, por fim, os vestígios papilares.

Cumpre salientar que essas duas proposições, ainda em 2012, se encontram em discussão entre os peritos. A distribuição das fotografias se ao longo da descrição ou no final do texto remete aos questionamentos sobre como se dará a interpretação por parte da autoridade, uma vez que o descolamento da sequência pode impedir uma visão mais ampla do local. A padronização dos laudos também encontra adeptos, bem como aqueles que consideram inexequível tal sistematização - afinal, como dizem, "o laudo é do perito". 


\section{0 que dizem as fotografias constantes dos laudos analisados}

Antes da análise das fotos, há que se fazer registrar as mudanças ocorridas ao longo do tempo. O número de fotos que compõem os laudos tem se mostrado maior, dada à facilidade e ao custo mais baixo na obtenção de imagens, embora a impressão ainda apresente um valor significativo em decorrência do cartucho colorido e o papel para impressão terem um preço alto. Todavia, os softwares para localização espacial são usados deixando imagens mais precisas sobre a geografia do lugar periciado. Um dos laudos analisados, datado de agosto de 2011, apresentou as fotografias inseridas ao longo do texto permitindo um acompanhamento daquilo que está sendo descrito com a respectiva imagem.

As teorizações apresentadas pelos estudiosos das Ciências Sociais (dentre eles, MARTINS, 2009) encontram ressonância nos laudos da perícia criminal. As fotos mostram o visível e o invisível. O visível é o corpo e aquilo que se acha em seu entorno. O invisível é a dinâmica do crime que as imagens ajudam a construir. A realidade está ali para ser registrada, a presença da vítima e de seus pertences, mas é a materialidade das manchas de sangue que vão auxiliar na identificação agora ausente do trajeto que a vítima percorreu após, por exemplo, ter sido atingida por vários disparos de arma de fogo. A luta corporal travada com o agressor vai ser identificada pelas marcas gravadas no corpo ou pelos objetos constantes do local, mas o momento da luta estará ausente, é invisível, já não existe mais: a fotografia vai mostrar também o ausente.

Nos laudos, a noção da fotografia como prova documental e representação, ambiguidade apontada por Kossoy (2002) e Andrade (2002), aparece de maneira perceptível. Há uma realidade que foi fotografada - a vítima, as manchas de sangue, o ferimento, as vestes -, mas há, também, uma representação que vai ocorrer por ocasião da análise, leitura, dessas fotos pelo perito que elaborará o laudo. Haverá igualmente uma leitura por parte do delegado da Polícia Civil, do Membro do Ministério Público, do Juiz, cada um desses atores terá uma possibilidade de interpretação sobre o que dizem as fotografias que integram o laudo.

Além disso, as fotografias do local vão mantê-lo visível por anos, todavia, esse local será desfeito tão logo a perícia der por encerrado os seus trabalhos. Ao ser retirada a fita amarela e preta que isola o local do crime, não haverá mais a 
possibilidade de refazê-lo, só as fotos irão mantê-lo preservado, de modo que o perito relembre e atente para mais alguns detalhes por ocasião da redação do laudo. O depoimento do perito A1 reflete essa relevância da foto: "Certa vez consegui observar um projétil em um local de crime pela ampliação das fotos. Voltei no local e ele realmente estava lá". Tal situação referenciada vai ao encontro daquilo que afirmou Barthes (1984) sobre a captura dos detalhes mediante o ato de fotografar.

Os registros das casas, das ruas, das vestes da vítima também informam acerca de uma época, das condições sociais da vila ou do espaço urbano ou rural; a casa da criança vitimada, registrada em fotos, informa da precariedade das instalações e dos móveis, a roupa da escola identifica o possível capital cultural que ela deve ter obtido até aquele momento. Os descampados de uma determinada época e região, mais tarde densamente povoados, revelarão as alterações da geografia da cidade. Os objetos de uso comum em uma determinada época e que não são mais encontrados (a não ser em museus) estão ali nas fotografias dos laudos, na descrição que revela terem sido utilizados para determinadas coisas que hoje são de total desconhecimento por parte dos mais jovens, e que as fotos ajudam a dar ciência sobre como eram e qual a serventia, revelando "a história visual de uma sociedade" (BITTENCOURT, 2004, p. 199).

Tomemos como exemplo dessa materialidade fotos de veículos, hoje só possíveis de serem apreciados em museus ou junto a colecionadores, constantes em laudos datados de 1952 em que se tem na descrição:

\footnotetext{
O automóvel, objeto do presente exame pericial, é de marca "Ford", V8, modelo 1946, sedan de quatro portas, cor azul marinho, aparentemente em bom estado de conservação, placas XXXXXX, aluguel. Os parabrisas e o envidraçamento geral do veículo estão constituídos por vidro de segurança, tipo "Triplex".

HISTÓRICO

O levantamento fotográfico do carro em apreço, solicitado verbalmente em 16 de setembro do corrente ano, foi procedido, sob orientação pessoal do relator do presente laudo, no dia imediato, pelo fotógrafo técnico dêste I. P. T., Sr. YYYYYY, às 10,30 horas, achando-se, nessa ocasião e para tal fim, recolhido o veículo à garage do $R$. C. $P$.
}

O laudo em questão ainda vem acompanhado de um esquema (croqui do automóvel) elaborado pelo perito mostrando a trajetória dos projetis. Esse laudo, além de trazer fotos de um veículo antigo, apresenta peculiaridades do cotidiano dos peritos de uma determinada época. Uma análise cuidadosa das fotografias desse veículo mostra as técnicas fotográficas da época: as fotos são em preto e branco, 
cada uma delas com bordas recortadas, dando um acabamento diferenciado, eram analógicas e reveladas em laboratório. O laudo apresenta-se datilografado, o que exigia por parte da pessoa que executava esse trabalho um cuidado especial para não efetuar rasuras, afinal, trata-se de um documento, mas no caso desse laudo objeto de análise verifica-se a inserção de um "t" manuscrito na palavra "resulado". Conforme foi possível verificar em outros laudos - na medida em que os manuscritos se encontravam anexos aos textos datilografados - o perito entregava 0 manuscrito que era datilografado por um servidor atuante na área administrativa.

Uma servidora que exerceu essa atividade de datilógrafa no DC relatou que naquela época havia muitas vezes dificuldade na compreensão do rascunho a ser datilografado e que era preciso esforço para decifrar a letra do perito. Em sua lembrança, a narrativa do que ocorreu em certa ocasião, quando disse a uma perita não estar entendendo o que ela, perita, havia escrito no rascunho do laudo, a resposta obtida foi a de que a servidora administrativa não tinha a necessidade de compreender nada, ao que a servidora na função de datilógrafa retrucou afirmando não ser possível realizar a tarefa sem compreender o que estava executando. Outro servidor relatou as inúmeras ocasiões em que datilografou laudos e que contou com a ajuda de um perito que ainda hoje atua no DC para elucidar algo que estava escrito de forma indecifrável. Esses são relatos de um cotidiano e de conflitos que não mais existem, uma vez que com o advento dos computadores pessoais os laudos passaram a ser digitados pelos próprios peritos.

Outro laudo, datado de 1952, busca verificar em uma criança, vítima de acidente de trânsito, vestígios ou impressões de veículos e comparar esses vestígios com os automóveis periciados, uma caminhonete Austin A 40, de cor cinza, placas XXXXXX e uma caminhonete Chevrolet 'Pavão', com carroceria de

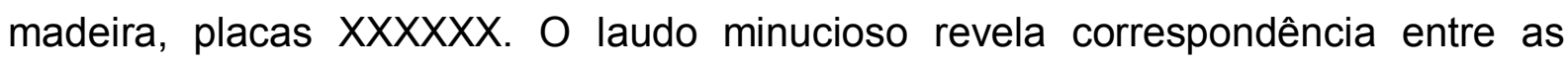
marcas no corpo do garoto e o rodado de um dos veículos, as fotos em preto e branco mostram a criança e os automóveis colocados sob perícia.

Segundo Monteiro (2004), na década de 1950, os carros e os ônibus vão ser os símbolos da modernidade em Porto Alegre, mas é nesse período igualmente que problemas de infraestrutura urbana, no que tange ao abastecimento de água, energia, esgotos, iluminação e transporte, vão se fazer sentir de modo mais acentuado em virtude do crescimento da cidade. 
Nos laudos de 1957, realizados em locais de incêndio, verifica-se as particularidades das construções daquela época. Em uma "casa de negócio" localizada em um porão habitável no centro de Porto Alegre, mais precisamente na Rua Riachuelo, onde eram comercializadas mercadorias de palha e vime, percebese que o porão com piso de cimento, sem forro, mas com energia elétrica, era acessado através de pequenos portões metálicos com grades.

O mesmo ocorre com o laudo do incêndio nas oficinas da Livraria do Globo, importante estabelecimento comercial em Porto Alegre por várias décadas, da qual também fazia parte a Editora do Globo, onde trabalharam Érico Veríssimo e Mário Quintana, escritores renomados no Rio Grande do Sul, no Brasil e no exterior. No dizer de Monteiro (2004), a Livraria do Globo estava entre os novos espaços de sociabilidade do início do século $\mathrm{XX}$, dividindo com cafés, confeitarias, restaurantes, cinemas e teatros aspectos da nova cultura urbana de Porto Alegre. O laudo de 1957 sobre a Livraria do Globo dá as características do local do sinistro mediante descrição e também através das fotos inseridas na parte a elas destinadas no final do laudo:

\footnotetext{
Trata-se, o local sinistrado, de um pavilhão de grandes dimensões, com as quatro paredes (que permaneceram em pé) de alvenaria de tijolos, todas as janelas de ferro, com respectivos vidros quebrados, chão cimentado, fôrro de madeira; o telhado comportava 3 cumieiras e era coberto com telhas de barro tipo "Marselha". Existia uma porta metálica de entrada e outra porta, à prova de fogo, comunicando êste pavilhão com outro, de parede comum.
}

Outro laudo do mesmo ano dá conta de um incêndio no galpão de madeira construído nos fundos do prédio onde funcionava a Escola de Artes e Ofícios do "Lar Amigo Germano". Cumpre destacar que a instituição "Lar Amigo Germano" existe até hoje, 2012. O laudo com fotos traz a seguinte descrição:

\footnotetext{
O local do sinistro constava de um galpão de madeira, recoberto com telhas de barro cozido, do tipo "marselha" e estivera construído, em meia água, junto à parede de alvenaria de tijolos do prédio principal, com a qual fazia divisão (fotos 1 e 2) [...]
}

As fotos e as descrições nos permitem ter contato com uma realidade citadina onde as construções guardavam certas semelhanças, as telhas "marselha", os pisos de cimento, os portões metálicos, presença de forro de madeira ou mesmo construções sem forro. 
Nos laudos analisados de 1965 e 1966, verifica-se que os peritos precisavam ter domínio sobre os tipos e demais detalhes das máquinas de escrever e de reproduzir documentos, de sorte a estarem aptos para identificar de onde provinham cartas anônimas, documentos falsificados, tais como carteira de identidade e carteira de motorista. As fotografias dão conta de como eram esses documentos no passado.

Uma perícia solicitada em 1966 revela os anos de ditadura militar, uma vez que foi encaminhado material gráfico, aparelhos duplicadores e papéis outros, bem como uma máquina de escrever portátil Olivetti. Dentre o material enviado para análise constavam: 1 exemplar do jornal "Combate", $n^{\circ} 6$ e 6/65; 1 exemplar do jornal "Opinião", n 3; 1 exemplar do Jornal "Voz Operária”, n 9; 1 exemplar do jornal "Ação Revolucionária", nº 5; 1 exemplar do jornal "Resistência Farroupilha", $n^{\circ}$ 1; 1 opúsculo "O operário em construção"; 1 opúsculo "A luta política nas condições de uma nova polarização"; 1 opúsculo "Resolução interna da Comissão Central do PCB"; 1 opúsculo "Pela Unidade do Povo Brasileiro"; 9 folhas de provas para jornal. O perito chama a atenção para o fato de não terem sido formulados quesitos a serem respondidos pela perícia, bem como sobre a grande quantidade de material enviado que não foi reproduzido em fotos no laudo, uma vez que demandaria enorme consumo de material fotográfico.

Aqui é possível ver o trabalho da perícia sendo solicitado com vistas a atender as deliberações de um regime autocrático que almejava "prender" e "torturar" quem fosse contrário aos ideais políticos vigentes. A prova técnica seria utilizada certamente para esses fins. Mesquita Neto (1999) afirma que, no período que se estendeu de 1964 a 1985, época do regime autoritário no Brasil, o governo promoveu e aceitou a violência policial como meio de controle político visando reprimir qualquer manifestação contrária ao regime instaurado. A perícia, a serviço da polícia, tinha de cumprir atribuições como a que aparece no laudo supramencionado. Todavia, pode-se pensar que consciente ou inconscientemente o perito que realizou a análise do material encaminhado não era favorável ao regime. Essas suposições decorrem da opção por não serem colocadas as fotografias, fato alegado em razão do alto consumo de material. Todavia, sabe-se que os detentores de poder na época não poupavam recursos para ver os seus objetivos de repressão atendidos. Outro indicativo de certa oposição aparece na sinalização de que os quesitos a serem respondidos estavam ausentes da solicitação, mas que o perito os 
havia deduzido. Ou seja, havia o conhecimento prévio por parte dos profissionais daquilo que preocupava os detentores do poder e que eles almejavam coibir mediante o uso da força para evitar o afloramento de ideologias divergentes.

Datados de 1968, dois levantamentos fotográficos mostram ocorrências envolvendo bondes em Porto Alegre. Um deles trata da colisão entre um bonde da Cia. Carris e uma camioneta Ford do Departamento Autônomo de Estradas de Rodagem, onde a camioneta foi arrastada pelo bonde. As fotos mostram a Avenida Osvaldo Aranha em Porto Alegre, o bonde de número 59 e a camioneta abalroada. O outro levantamento fotográfico registra o local onde o bonde de $n^{0} 116$ atropela uma transeunte que não estava no local, uma vez que fora encaminhada para o Hospital de Pronto Socorro. Os trilhos do bonde são visíveis em um local de morte, na Rua Cristóvão Colombo, a vítima jazia próxima a eles. A cidade de Porto Alegre teve em seu cenário urbano a presença dos bondes até 1970, ocasião em que esse meio de transporte foi retirado de cena (MONTEIRO, 2004) e os trilhos das ruas e avenidas foram retirados ou cobertos por camadas de asfalto.

Um dos levantamentos realizados em 1973 apresenta um registro que no cotidiano atual dos peritos tem sido mencionado, nas conversas ou entrevistas realizadas, como sendo um "cheiro que a gente nunca esquece". Consta no texto: "No referido apartamento (onde foi possível entrar somente com o uso de máscaras anti-gases devido aos fortes odores de putrefação) encontramos um cadáver de aspecto gigantesco em adiantado estado de decomposição". E mais adiante: "o corpo estava cercado por moscas e tomado por larvas (fotos $n^{\circ} 3,6$ e 7)". As fotos revelam a presença das moscas e larvas, mas a de número 7 traz um rosto totalmente deformado, com uma expressão assustadora.

A partir da década de 1950 as diferenças sociais fizeram-se sentir de modo mais intenso, com a formação de vilas populares e de bairros das camadas abastadas; a segregação social se impunha de forma acentuada na cidade de Porto Alegre, agravando-se a marginalização, a periferização e a violência, situação que se expandiu nos anos subsequentes (MONTEIRO, 2004).

Um laudo de janeiro de 1973 revela o levantamento em local de morte de um homem que recebeu às 8h20min uma ordem de despejo de um fiscal da Prefeitura Municipal de Porto Alegre. O fiscal relatou que a vítima sabia que deveria deixar a casa nas dias subsequentes, mas mostrou surpresa com a intimação para a deixar naquele mesmo dia. Dez minutos após a saída do fiscal, os vizinhos ouviram 
estampido de arma de fogo proveniente do interior da referida moradia, que na descrição do perito tratava-se de uma "maloca" constituída por duas peças. Esse laudo revela aquilo a que fez alusão Monteiro (2004), a pauperização da cidade. A linguagem constante no laudo também reflete a terminologia da época ao tratar a moradia como "maloca". Ao visualizar a fotografia da moradia, é possível afirmar que nos laudos de hoje provavelmente a definição a ser usada seria a de um "casebre".

Os laudos das décadas de 1970 e 1980 ainda possuíam uma capa, algo que foi abolido nos laudos de décadas seguintes - de 1990 até 2011 - visando reduzir custos. Quando envoltos nessa capa, os laudos tinham internamente uma divisória depois da qual eram inseridas as fotografias, nessa divisória havia um retângulo que continha uma ressalva: "É vedado o uso das presentes fotografias desacompanhadas do respectivo laudo pericial do Instituto de Criminalística" (antes da autonomia, Instituto de Polícia Técnica). Em anos recentes, as folhas finais dos laudos possuem em seu cabeçalho a seguinte indicação: "Suporte para fotografias de trabalhos periciais".

Vários levantamentos fotográficos foram encontrados em anos temporalmente mais distantes, mas as fotos por si só, no entender da atual Direção do DC, permitiriam manipulações na interpretação e, para evitar distorções, foi, em 2011, expedida uma ordem de serviço que "determina que os Postos de Criminalística, mesmo quando solicitados, não realizarão mais Levantamento Fotográfico em local de crime". Dentre as considerações tecidas para essa instrução, há a de que não existe embasamento legal que autorize a dispensa de um perito em local de crime em detrimento do levantamento fotográfico e, ainda, "que a fotografia não substitui o exame pericial de Corpo de Delito ou dos vestígios da infração, de acordo com o art. 165 do Código de Processo Penal". O registro de uma entrevista realizada com uma servidora aposentada dava conta de que no passado, em certas ocasiões, o perito se omitia de realizar o seu trabalho no local, cabendo somente ao fotógrafo fazer os registros que depois seriam analisados. A ordem de serviço emitida em 2011 impede a ocorrência dessas distorções e coloca a fotografia e o texto como duas linguagens sobre o mesmo fato, que devem ser complementares. A direção do DC toma uma decisão consoante com aquilo que postula Kossoy (2002) sobre a manipulação das fotografias e suas possíveis interpretações. 
Nos laudos de décadas passadas, a solicitação de perícia em certas circunstâncias era feita de maneira verbal pela autoridade policial. Hoje, com a informatização, a solicitação é feita por meio eletrônico, portanto, documentada.

O laudo diz muito mais do que os aspectos técnicos registrados pelos peritos e fotógrafos criminalísticos: o laudo revela a dinâmica das pessoas, das cidades, dos praticantes de atos criminosos, das vítimas, das etnias mais susceptíveis a determinadas atrocidades. O laudo traz elementos para além daquilo que a perícia pretende, ou seja, a culpabilização do criminoso ou a absolvição do inocente, o laudo e principalmente as fotografias falam de uma sociedade dizendo "ao homem em cada época, quem o homem é" (MARTINS, 2009, p. 20), bem como da sua relação com os outros homens. Mostra também as mudanças técnicas e as continuidades no trabalho da perícia.

\section{Considerações finais}

O objetivo deste artigo, que era o de analisar fotografia e história no cotidiano laboral dos peritos criminais através do estudo dos laudos do Departamento de Criminalística do Instituto-Geral de Perícias do Rio Grande do Sul, foi alcançado na medida em que as fotografias que integram os laudos passam a ser reveladoras de uma realidade, mas também trazem o ausente, com toda a ambiguidade que a foto tende a apresentar. Tal característica da fotografia - mas que também se estende para outros documentos - torna pertinente as discussões entabuladas no Primeiro Congresso Nacional de Polícia Técnica sobre a posição das imagens nos laudos. A padronização dos laudos que vem na esteira dessa discussão também teve início na década de quarenta do século passado e ainda se apresenta como uma pauta de discussões, o que revela a dificuldade de estruturação de um fazer que lida com a "verdade", mas que a despeito da materialidade da prova não consegue escapar da subjetividade, algo inerente a todo o fazer científico que há muito tempo já viu cair por terra a "neutralidade".

Importante chamar a atenção que as fotos e as descrições constantes nos laudos apresentam o olhar dos peritos e fotógrafos criminais, portanto, dizem respeito a um fazer cotidiano específico que busca inocentar ou incriminar mediante as provas técnicas - o autor de um delito. 
A historiadora Arend (1994, p. 71), ao estudar os autos de processos sob o ponto de vista da História, preconiza que: "Um conhecido brocardo afirma que 'o que não está nos autos não está no mundo. Para o historiador, os autos revelam 'mundos'; todavia, para que isso aconteça ele deve enxergar além dos autos". Assim, parafraseando Arend (1994), para que se possa desnudar o cotidiano laboral da perícia é preciso enxergar para além dos laudos, o visível e o invisível. 


\section{REFERÊNCIAS}

ANGROSINO, Michael. Etnografia e observação participante. Porto Alegre: Artmed, 2009.

AREND, Silvia Maria Favero. Considerações acerca do uso dos processos penais como fonte documental para historiadores. Maria degolada: mito ou realidade? Arquivo Púbico do Estado do Rio Grande do Sul. Porto Alegre: EST, 1994.

ABREU, George. Modelo prático de apresentação de laudo pericial. In: PRIMEIRO CONGRESSO NACIONAL DE POLÍCIA TÉCNICA. São Paulo, 1947. Anais... 1950, p. $169-170$.

ANDRADE, Rosane de. Fotografia e Antropologia: olhares fora-dentro. São Paulo: Estação Liberdade/EDUC, 2002.

BARTHES, Roland. A câmara clara. Rio de Janeiro: Nova Fronteira, 1984.

BITTENCOURT, Luciana Aguiar. Algumas considerações sobre o uso da imagem fotográfica na pesquisa antropológica. In: FELDMAN-BIANCO, Bela; LEITE, Míriam L. Moreira. (orgs.). Desafios da imagem: fotografia, iconografia e vídeo nas Ciências Sociais. Campinas: Papirus, 2004, p. 197-211.

BORGES, Maria Eliza Linhares. História \& Fotografia. Belo Horizonte: Autêntica, 2008.

CHIZZOTTI, Antonio. Pesquisa em Ciências Humanas e Sociais. São Paulo: Cortez, 1995.

DA COSTA FILHO, Paulo Enio Garcia; ABDALLA-FILHO, Elias. Diretrizes éticas na prática da perícia criminal. Revista Bioética. 18 (2), p. 421-437, 2010.

ÉBOLI, Carlos de Mello. Sistematização dos relatórios e laudos. In: PRIMEIRO CONGRESSO NACIONAL DE POLÍCIA TÉCNICA. São Paulo, 1947. Anais... p. 149-153, 1950. 
INSTITUTO-GERAL DE PERÍCIAS - Departamento de Criminalística. Disponível em <http://www.igp.rs.gov.br/>. Acessado em: 16 out. 2011.

KOSSOY, Boris. Realidades e ficções na trama fotográfica. Cotia: Ateliê Editorial, 2002.

LEWGOY, Flávio. Pequeno guia de levantamento de locais. Revista de Criminalística do Rio Grande do Sul. Ano 10, v. 2, n.12. Porto Alegre, p. 767-792, jul. 1972.

LOCARD, Edmond. A investigação criminal e os métodos científicos. São Paulo: Saraiva, 1939.

MALLMITH, Décio de Moura. Local de Crime. Porto Alegre: Departamento de Criminalística do Rio Grande do Sul, 2003.

MARTINS, José de Souza. Sociologia da fotografia e da imagem. São Paulo: Contexto, 2009.

MESQUITA NETO, Paulo. Violência policial no Brasil: abordagens teóricas e práticas de controle. In: PANDOLFI, Dulce et al. Cidadania, justiça e violência. Rio de Janeiro: Fundação Getúlio Vargas, 1999, p. 130-148.

MONTEIRO, Charles. Porto Alegre no século XX: crescimento urbano e mudanças sociais. In: DORNELLES, Beatriz. Porto Alegre em destaque: História e Cultura. Porto Alegre: EDIPUCRS, 2004.

RABELLO, Eraldo. Contribuição ao estudo dos locais de crime. Revista de Criminalística do Rio Grande do Sul. Ano 6, n.7, Porto Alegre, p. 51 - 97, jul. 1968.

SILVEYRA, Jorge O. Investigatión científica del delito: la escena del crimen. Buenos Aires: La Rocca, 2006.

Artigo:

Recebido em: 23/07/2012

Aceito em: 20/12/2012 